\title{
The Prenatal Environment in Twin Studies: A Review on Chorionicity
}

\author{
Kristine Marceau $^{1,3,7}$ (1) Minni T. B. McMaster ${ }^{5}$ Taylor F. Smith ${ }^{1,4}$ • \\ Joost G. Daams ${ }^{6}$ - Catharina E. M. van Beijsterveldt ${ }^{5}$ - Dorret I. Boomsma ${ }^{5}$. \\ Valerie S. Knopik ${ }^{1,2}$
}

Received: 5 October 2015/Accepted: 1 January 2016/Published online: 5 March 2016

(c) The Author(s) 2016. This article is published with open access at Springerlink.com

\begin{abstract}
A literature search was conducted to identify articles examining the association of chorionicity (e.g., whether twins share a single chorion and thus placenta or have separate chorions/placentas) and genetics, psychiatry/ behavior, and neurological manifestations in humans twins and higher-order multiples. The main aim was to assess how frequently chorionicity has been examined in relation to heritability estimates, and to assess which phenotypes may be most sensitive to, or affected by, bias in heritability
\end{abstract}

Dorret I. Boomsma and Valerie S Knopik-shared last author position.

Electronic supplementary material The online version of this article (doi:10.1007/s10519-016-9782-6) contains supplementary material, which is available to authorized users.

Dorret I. Boomsma

di.boomsma@vu.nl

Kristine Marceau

Kristine_Marceau@Brown.edu

1 Division of Behavioral Genetics, Department of Psychiatry, Rhode Island Hospital, Providence, RI, USA

2 Department of Psychiatry and Human Behavior, Brown University, Providence, RI, USA

3 Center for Alcohol and Addiction Studies, Brown University, Providence, RI, USA

4 Department of Psychology and Child Development, California Polytechnic State University, San Luis Obispo, CA, USA

5 EMGO Institute for Health and Care Research, VU University, Amsterdam, The Netherlands

6 Academic Medical Center, Medical Library, University of Amsterdam, Amsterdam, The Netherlands estimates because of chorionicity. Consistent with the theory that some chorionicity effects could lead to overestimation and others to underestimation of heritability, there were instances of each across the many phenotypes reviewed. However, firm conclusions should not be drawn since some of the outcomes were only examined in one or few studies and often sample sizes were small. While the evidence for bias due to chorionicity was mixed or null for many outcomes, results do, however, consistently suggest that heritability estimates are underestimated for measures of birth weight and early growth when chorionicity is not taken into account.

Keywords Chorionicity - Genetics · Heritability · Prenatal environment . Twins

\section{Introduction}

Twin studies have long been used to estimate the unique contributions of genetic and environmental influences on variation in human traits. One assumption of the quantitative genetic theory underlying twin studies is the equal environments assumption, which states that the exposure to environmental events that create resemblance between cotwins for the trait under study is equal for monozygotic (MZ) and dizygotic (DZ) twin pairs (Loehlin and Nichols 1976; Scarr and Carter-Saltzman 1979). The prenatal environment is a specific and crucial environmental influence on many human traits (Barker 1990), and while twins and higher-order multiples share the womb, the prenatal environment may not be equal for both twins in a pair, or for other higher-order multiples. Thus, the prenatal environment cannot necessarily be considered as an environmental factor creating resemblance in children sharing the 
womb at the same time. How twins experience the prenatal environment depends, in part, on chorionicity, i.e., whether twins share a single chorion (monochorionic, $\mathrm{MC}$ ) or have separate chorions (dichorionic, DC). Monozygotic (MZ) twins can be mono- or dichorionic, whereas dizygotic twins are dichorionic.

In this review, we first introduce the concepts of the chorion, amnion, and placenta. Next, we discuss how chorionicity may shape the prenatal environment of twins and higher-order multiples and aim to summarize the types of outcomes that have been linked to chorionicity. Finally we review and summarize studies which have examined the influence of chorionicity on twin-based heritability estimates in order to draw conclusions about whether chorionicity introduces bias and, if there is bias, whether this bias affects phenotypes in a consistent manner.

\section{Chorionicity}

The chorion is the outer-most fetal membrane that contains the amnion/amniotic sac. The amnion is the thin inner-most fetal membrane that protects the embryo/fetus and contains amniotic fluid. The chorion connects the amnion, amniotic sac, and the fetus to the placenta and contributes to placental development. Thus, if twins share a chorion (e.g., are monochorionic or MC) they will share a single placenta, whereas twins with separate chorions (e.g., dichorionic or DC twins) develop individual placentas. DZ twins are dichorionic, since they form from two separately fertilized eggs, although very rare exceptions have been described in the literature (e.g., Souter et al. 2003). Figure $1 \mathrm{a}, \mathrm{b}$ provides an illustration of the multiple ways cotwins can share the chorion and amnion. Figures 2, 3, 4 show ultrasound images of monochorionic (Fig. 2), dichorionic (Fig. 3), and trichorionic triplets (Fig. 4). Generally, it is thought that the timing of division of the blastocyst/embryo determines amnionicity and chorionicity (Hall 2003; De Paepe 2015), such that later cleavage (e.g., between 4 and 13 days) leads to MC twins and earlier cleavage (e.g., before 4 days) leads to DC twins. Later cleavage (e.g., 8-13 days) may lead to monoamniotic twins and earlier cleavage (e.g. before 8 days) to diamniotic twins. However, what determines whether and when a fertilized egg splits, and if the resulting MZ twins (or triplets or other higher order multiples) will develop separate chorions, are questions for which very little empirical data are available (Knopman et al. 2014; Herranz 2015).

\section{Prevalence}

Epidemiological data indicate that the MZ twin prevalence is fairly consistent at around 4 per 1000 maternities worldwide (Tong et al. 1997). DZ twinning rates differ

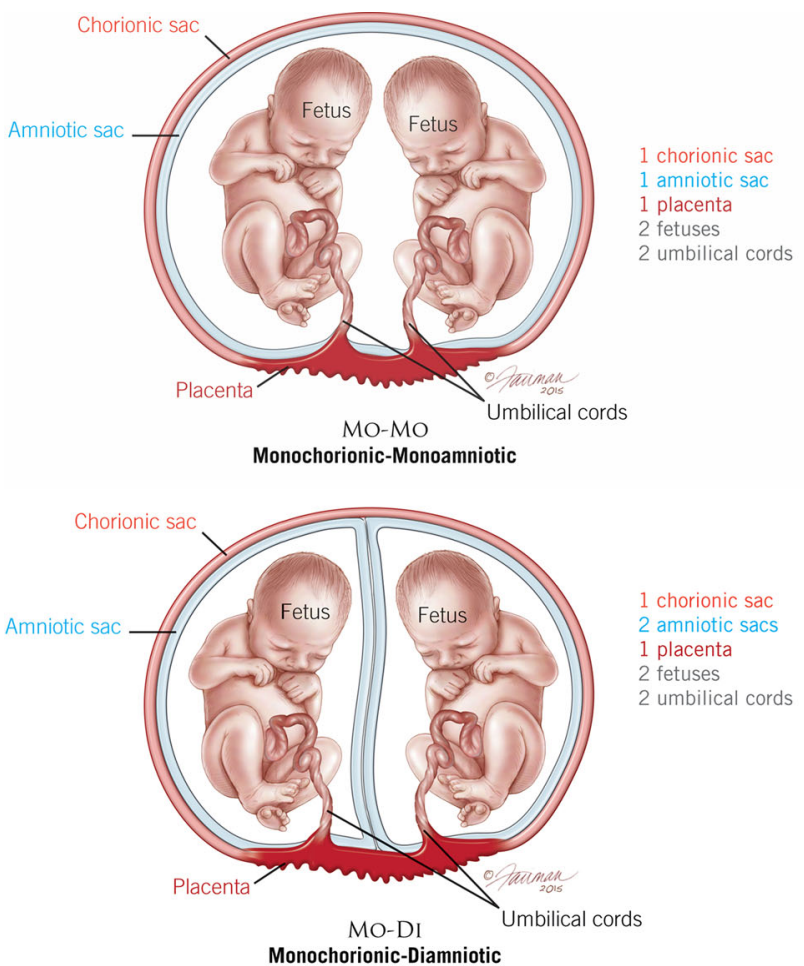

(a)

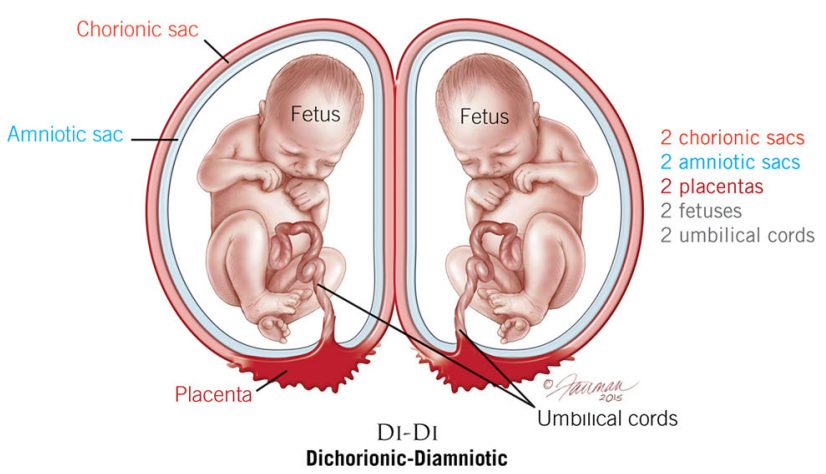

(b)

Fig. 1 a Monochorionic-monoamniotic twins (MCMA, shown in the top image) have 1 chorion and 1 amnion. Monochorionic-diamniotic twins (MCDA, shown in the bottom image) have 1 chorion and 2 amnions. MC twins (whether MCMA or MCDA) share the same placenta. (C2015, Jennifer Fairman, CMI, FAMI. Published with permission. b Dichorionic-Diamniotic (DCDA) twins have two chorions and two amnions. Diamniotic twins can have the same or different placentas. (C) 2015, Jennifer Fairman, CMI, FAMI. Published with permission

around the globe and over time (e.g., increasing with maternal age and as artificial reproductive techniques have become more widely available and used; Hoekstra et al. 2008). For example, among Caucasian populations (e.g., United States, Europe, Australia), total twinning rates were estimated at 15-16 per 1000 in 2003 (Hoekstra et al. 2008), whereas Asian countries had lower rates at about 9 per 1000 (Smits and Monden 2011; Hoekstra et al. 2008). 


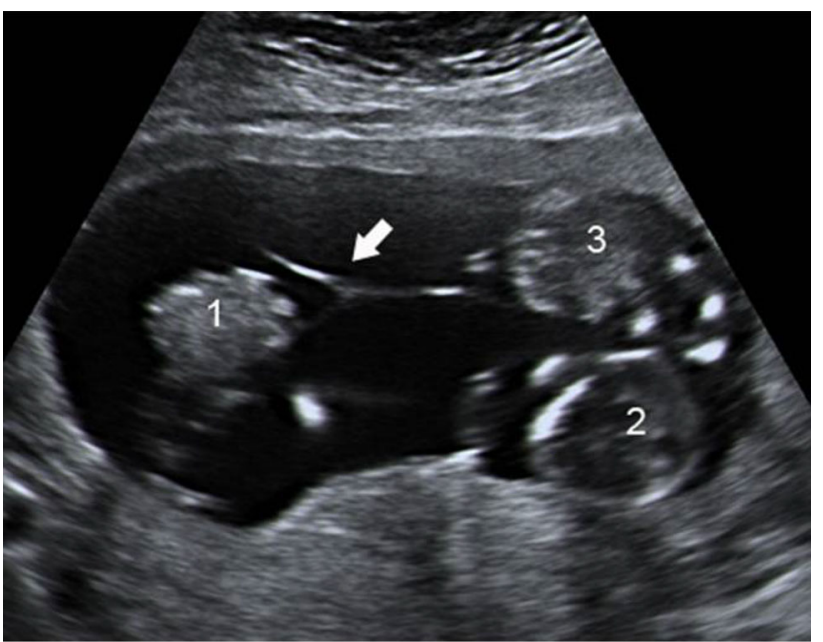

Mono-chorionic triplets

Fig. 2 Ultrasound picture of a monochorionic, and therefore monozygotic trio at 12 weeks gestational age. The arrow indicates the meeting pointing point of three amniotic membranes. Numbers indicate the three fetuses. (Used with permission from Lamb et al. 2012)

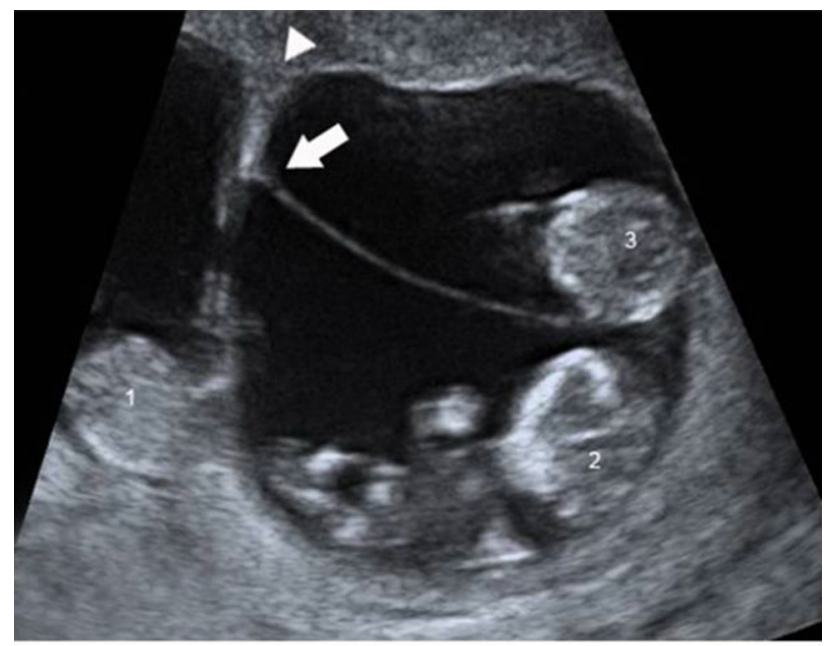

Di-chorionic triplets

Fig. 3 Ultrasound picture of a dichorionic, triamniotic trio at 13 weeks gestational age. The arrow indicates the amniotic membranes of fetuses 2 and 3, which are a monozygotic pair. At this time, it is unsure if Fetus 1 shares zygosity with fetuses 2 and 3. Numbers indicate the three fetuses. (Used with permission from Lamb et al. 2012)

African populations have higher twinning rates, of about 12-18 in sub-Saharan countries and over 18 per 1000 in central African countries (Smits and Monden 2011). Thus, in Caucasian and sub-Saharan African populations, MZ twins comprise $\sim 26 \%$ of all twins, whereas in Asian populations, $\mathrm{MZ}$ twins represent over half of all twins, and

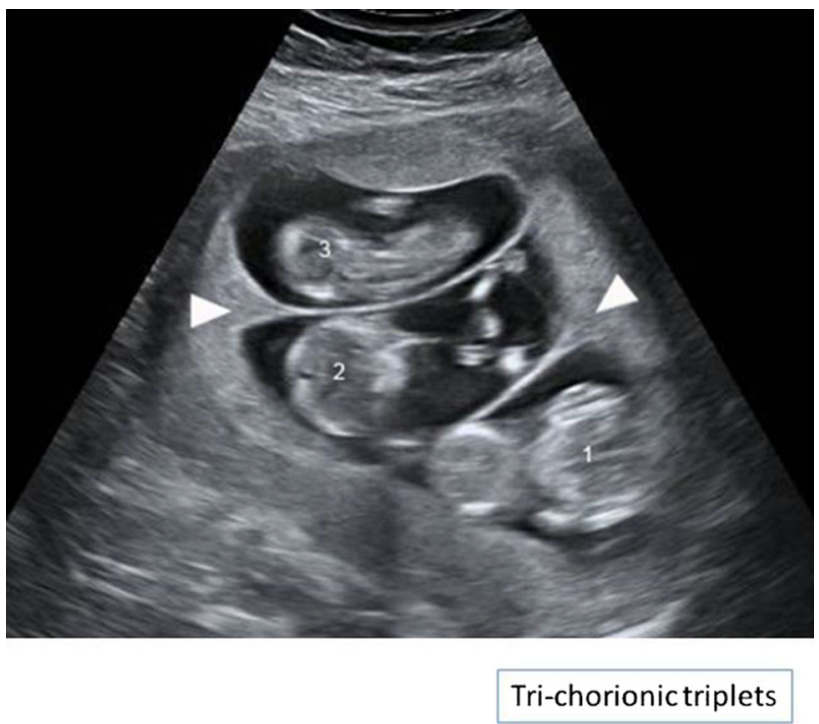

Fig. 4 Ultrasound picture of a trichorionic trio at 12 weeks gestational age. These three fetuses do not share their placentas. This trio can be trizygotic, dizygotic (one identical duo), or monozygotic. Numbers indicate the three fetuses. (Used with permission from Lamb et al. 2012)

in central African populations $\mathrm{MZ}$ twins represent less than $5 \%$ of all twins. Given that heritability estimates are specific to the population being studied, differences in the prevalence of $\mathrm{MZ}$ and DZ twins in different populations will likely affect the extent to which chorionicity might affect heritability estimates in these populations.

Of all MZ twin pairs, about two-thirds (70-74\%) are monochorionic (MZ-MC) and one-third (35-30\%) are dichorionic (MZ-DC) (Hall 2003). However, 1-2 \% of MZ twin pairs are monoamniotic (Hall 2003) although this percentage varies by sample. Given the low prevalence of monoamniotic twins this review focuses on the potential effects of chorionicity rather than amnionicity. For Caucasian populations (where most twin research has been done) about $17 \%$ of all twin pairs are MZ-MC, 9\% are MZ-DC, and $\sim 74 \%$ are DZ-DC. However, the proportion of MZ-MC, MZ-DC, and DZ-DC twins in any given study varies widely and is not always reported (Petterson et al. 1998).

\section{Determination}

A large body of literature has examined appropriate ways to determine chorionicity. Prospectively, chorionicity is best determined via ultrasound. Determining chorionicity is highly accurate $(96 \%)$ by ultrasound in the first trimester, though still accurate $(80 \%)$ in the second (e.g., see Audibert and Gagnon 2011 for review; Machin 2004). Placental pathology examination also provides a direct assessment of chorionicity shortly after birth (De Paepe 
2015). Retrospective self-report determination of chorion type, for example by asking twin participants "how many placentas" there were at birth, has been suggested to be unreliable: $60 \%$ accurate for $\mathrm{MZ}$ and $37 \%$ accurate for DZ twins (Derom et al. 2003). Some studies have also tried to use dermatoglyphics to retrospectively determine chorionicity (e.g., Davis et al. 1995; Reed et al. 1991, 1978, 2002; Melnick and Myrianthopoulos 1979; Steinman 2001). Placental pathology examination and ultrasound appear to be the most reliable methods of determining chorionicity; thus, for the remainder of this paper we focus on studies which employed one of these two methods.

\section{Placental function}

The MC placenta functions like a single placenta, although a single placenta was not designed to support the growth of two fetuses. Therefore, MC placentation has a profoundly different biology than DC placentation. The greatest danger associated with MC placentation is related to the structure of blood vessels. One twin usually has better placement and therefore receives more of the nutrients. Inter-fetal vascular connections also form vascular anastomoses (i.e., the joining of two blood vessels) and connect the circulation of one twin to the circulation of the other, so in some pregnancies, there is direct blood sharing of MC twins. These inter-fetal vascular connections rarely form in DC twin pairs (Machin and Bamforth 1996; Phillips 1993).

Unequal placental sharing is a major cause of fetal growth discordance in MZ twins (Chang 2008; ClearyGoldman and D'Alton 2008; Nikkels et al. 2008). For example, specific reductions in five amino acids have been shown to explain discordant growth in MZ twins, suggesting that the inter-twin distribution of blood and nutrients accounts for within-pair differences in birth weight, as opposed to more general placental dysfunction (Bajoria et al. 2001). Extreme discordant growth due to unequal placental sharing can result in twin-to-twin transfusion (TTTS) syndrome, a severe pregnancy complication unique to $\mathrm{MC}$ twin pairs where there is also direct blood sharing (occurring in 5-30\% of MC twin pairs; Haverkamp et al. 2001; Phillips 1993). The imbalanced blood flow and twinto-twin transfusion has been reported to influence MZ twin resemblance for birth weight (see Foley et al. 2000 for review, and supplemental Table 1). These findings result in a difference in MC and DC twins for some birth outcomes including birth weight discordance, as MC twins are more likely to have higher birth weight discordance than DC twins who do not share a placenta.

The placenta also functions as a barrier, allowing small molecules (e.g., gases, nutrients, waste material, antibodies) to pass between mothers and children through passive transport (Page 1993; Schneider 1991). Other small molecules that may have an effect of fetal development (e.g., some maternal hormones like cortisol; bacteria; teratogens such as illicit drugs) can also be diffused through the placenta (van der Aa et al. 1998; Page 1993). Thus, the composition of the placenta and efficiency of transport between mother and child can affect fetal development. The placenta also functions as an endocrine organ (Melmed et al. 2012), synthesizing a large array of hormones (e.g., sex steroids and protein hormones) and cytokines that play a key role in fetal development (and maternal endocrine function). There are individual differences in hormone production, and sharing a placenta may lead to similarities in MC twins that are related to the levels and changes in placental hormone production relative to DC twins. Sharing a placenta in this case may lead to more similar in utero environments for MC twins relative to DC twins. However, endocrine function is, to some extent, linked to the vascular system, and the amount of pathogen, infection, nutrient, and gas and waste diffusion may also be linked to the proportion of the placenta dedicated to each child (Melmed et al. 2012). The potential impact of diffusion and endocrine function on similarity and differences of $\mathrm{MC}$ versus DC twins has not, to our knowledge, been investigated and is potentially an important area for future research. Thus, while some placental mechanisms (diffusion and endocrine function) may lead to more similar whereas others (unequal sharing of the vascular system) may lead to more different in utero environments, these mechanisms are linked and so the reality is less clear-cut.

\section{Chorionicity and heritability}

Because of the placental mechanisms leading to similarities and differences of the in utero environments for twins of different types, chorionicity may bias the heritability estimates found in twin studies (see Table 1). The potential challenge that chorionicity plays in the validity of twin studies is not a new concept (Price 1950), and has been highlighted in a number of studies (Derom et al. 2001; Foley et al. 2000; Munsinger 1977; O’Brien and Hay 1987; Phelps et al. 1997; Prescott et al. 1999; Price 1950). The prenatal environment could be more similar for MC twins relative to DC twins because of the shared chorion, or less similar because of the vascular and placental sharing inequalities often observed in MC but not DC pregnancies. Vascular differences found in MC twins often lead to differences in intrauterine growth of the twins, and thus MC twins can appear quite dissimilar especially early in life. If zygosity is only determined via questionnaire, MC twins may be misclassified as DZ twins, which would bias results of twin studies (Machin 2001, 2009). Even with correct classification, if MC twins are more dissimilar because of unequal placental sharing, then heritability estimates may 
Table 1 Mechanisms of potential bias in heritability estimates due to chorionicity

\begin{tabular}{|c|c|c|c|}
\hline $\begin{array}{l}\text { Mechanism of } \\
\text { chorionicity effects }\end{array}$ & $\mathrm{MC}$ and DC twin similarity & $\begin{array}{l}\text { Bias in } \\
\text { heritability } \\
\text { estimate }\end{array}$ & Rationale \\
\hline $\begin{array}{l}\text { Vascular differences: } \\
\text { placental sharing } \\
\text { inequalities }\end{array}$ & $\begin{array}{l}\text { MC twins less similar than DC } \\
\text { twins }\end{array}$ & Underestimated & $\begin{array}{l}\text { MZ twins would have lower correlation, closer to DZ twins } \\
\text { (reducing contrast) }\end{array}$ \\
\hline $\begin{array}{l}\text { Similar placental } \\
\text { function: diffusion, } \\
\text { osmosis, endocrine }\end{array}$ & $\begin{array}{l}\text { MC twins more similar than } \\
\text { DC twins }\end{array}$ & Overestimated & $\begin{array}{l}\text { MZ twins would have higher correlations than DZ twins, } \\
\text { chorionicity effect would be included in heritability estimate }\end{array}$ \\
\hline $\begin{array}{l}\text { Mis-classification of MZ } \\
\text { and DZ twins }\end{array}$ & $\begin{array}{l}\text { MC twins that are less similar } \\
\text { may be called DZ instead of } \\
\text { MZ twins }\end{array}$ & $\begin{array}{l}\text { Most likely } \\
\text { underestimated }\end{array}$ & $\begin{array}{l}\text { Including } \mathrm{MZ} \text { twins in } \mathrm{DZ} \text { group would mean more genetic } \\
\text { similarity in } \mathrm{DZ} \text { group, reducing contrast in twin correlations }\end{array}$ \\
\hline $\begin{array}{l}\text { MC twins have poorer } \\
\text { outcomes than DC } \\
\text { twins }\end{array}$ & $\begin{array}{l}\text { MC twins less or more similar } \\
\text { to DZ twins }\end{array}$ & $\begin{array}{l}\text { Underestimated } \\
\text { or } \\
\text { Overestimated }\end{array}$ & $\begin{array}{l}\text { MC twinning is indicative of a prenatal environmental risk } \\
\text { factor(s). If the MC twinning environmental factor(s) is } \\
\text { shared, MZ twins would have a higher correlation than DZ } \\
\text { twins; if the MC twinning factor was unshared, the MZ twins } \\
\text { would have a lower correlation, closer to DZ twins. }\end{array}$ \\
\hline
\end{tabular}

be underestimated because MZ twins would have a lower correlation, closer to that of DZ twin pairs (Price 1950). That is, the subset of MZ-DC twins may be more similar to DZ-DC and less similar to MZ-MC twins in their sibling correlations. This would, in turn, affect the intra-class correlations for MZ and DZ pairs (e.g., reduce the contrast) and downwardly bias the estimates of heritability. Further, MC twins often have poorer outcomes than DC twins (see review below and Supplemental Table). This may lead to mean-level or variance differences in the outcomes between MC and DC twins due to a possible violation of the equal environments assumption, which could also bias heritability estimates. For example, if in a pair of MC twins, one of the twins is at increased risk for a particular outcome (e.g., through limited blood supply because of TTTS), then the prenatal environment is not 'shared' although the MC status is considered 'shared'.

However, if sharing a placenta makes twins more similar because of similar intrauterine environments (e.g., passive transport), then the potential bias could indeed operate in the opposite direction, leading to overestimation of genetic influences (Phillips 1993). For example, MC pairs may be more likely to experience the same environmental exposures and pathogens, including infections and substance use exposure (Prescott et al. 1999). The crux of understanding how chorionicity may influence heritability estimates lies in understanding whether the prenatal environment is more or less similar for MC twins, and for which outcomes chorionicity matters for twin similarity.

This 'chorionicity debate' led to the proposal for chorion-control studies, where MZ-MC twins are compared with MZ-DC twins on a specific trait, or multiple traits, and a call for including chorionicity in classical twin studies (Phelps et al. 1997). However, methodological challenges have made the examination of the potential role of chorionicity difficult and largely theoretical; as noted above, a reliable assessment of chorionicity ideally requires placental pathology examination or prenatal ultrasound. As there is an increasing interest in simultaneously examining prenatal and genetic influences as exemplified in this special issue of Behavior Genetics, it is important to revisit the question of whether chorionicity may influence outcome variables assessed in twin studies and whether such influence could bias heritability estimates from studies that include predominantly twins.

\section{Method}

\section{Medical library database search}

The purpose of the literature search was to identify articles examining associations of chorionicity and genetics, psychiatry/behavior, and neurological manifestations in humans (twins/multiples). We searched PubMed (yielding 2111 articles after deleting duplicates), Embase, 1947 to present, OvidSP (yielding 1455 articles after deleting duplicates), and PsycINFO 1806 to Present (yielding 138 articles after deleting duplicates). The entire search strategy, including all search terms for each database, is included in Appendix. A variety of search terms were used (both text words [tw] and the PubMed search also included Medical Subject Heading terms [MeSH]), including but not limited to variants of multiple birth (e.g., multiple birth, twin), chorionicity (e.g., chorion, monochori*, dichori*, placentation), genetics (e.g., genetic*, epigenetic*, gene, genes, genotype), intelligence (e.g., intelligence, IQ), psychiatry/behavior (e.g., psychology, psychiatry*, mental, psychology*, behavior, neuropsych), neurological manifestations (e.g., neuromorbidity, neurologic*), and 
concordance/discordance (e.g., twin, discordan*, concordan*). In Embase, twin concordance and discordance was searched in combination with the outcome separately because of poor representation of chorionicity in the bibliographic records. Animal studies were excluded in all searches. We did not filter by language or date of publication. After duplicates from the multiple searches were excluded, there were a total of 2920 unique articles.

\section{Selecting relevant articles}

Each of the abstracts of the 2920 articles were read and judged for relevance to chorionicity and genetics/behavior/ psychiatry (e.g., identifying sources which examine the association of chorionicity with behavioral outcomes). Full texts were also searched for "chor" to aid with determining whether articles were relevant. Case studies and non-empirical articles were excluded from the final selections. We also excluded studies that used retrospective report of chorionicity as well as other alternative proxies for chorionicity (e.g., birth weight discordance, handedness, mirroring). At the end of this culling, 307 articles were identified as potentially relevant.

These 307 articles were further classified into background/review articles $(n=68)$, studies that compare the prevalence of various outcomes stratified by chorionicity (reviewed below and in the Supplementary Table, $n=134)$, studies that examined chorionicity effects in the context of behavioral genetic designs $(n=38)$, epigenetic studies $(n=5)$, and irrelevant studies (e.g., not examining chorionicity directly, or conference abstracts which may be preliminary and not peer reviewed, vetted findings, $n=62$ ). This sorting was done by reading the abstracts and articles to the depth required to make a decision. Of primary interest for the current review were the studies that examined chorionicity effects in the context of behavioral genetic designs. These studies were reviewed in detail in order to conclude whether chorionicity may bias results of heritability estimates for the diverse outcomes studied. We did not restrict our search based on outcomes during this phase.

\section{Results}

\section{Chorionicity and prevalence of birth outcomes and human traits}

A very large body of literature has examined whether there are prevalence differences in various birth, perinatal, and other outcomes based on chorionicity (see Supplementary Table for a summary of the 134 articles reviewed). The best-characterized outcomes influenced by chorionicity include immediate pregnancy and birth outcomes rather than longer term growth and psychiatric outcomes. We highlight the most consistent findings here (see Supplementary Table for details and exceptions). Most studies found that MC pregnancy infers higher risk of mortality than DC pregnancies (see Supplementary Table), but effects are not always consistent (e.g., Baghdadi et al. 2003; Lenis-Cordoba et al. 2013). Fetal growth has also been robustly linked with chorionicity. For example, birth weight discordance occurs more frequently in MC twins than DC twins (although this effect is not found in every study). Further, MC twins generally have lower birth weight (especially the smaller twin), lower birth weight after adjusting for gestational age (Ananth et al. 1998; Shrim et al. 2010), and shorter crown-rump length. Intrauterine growth restriction is more prevalent in $\mathrm{MC}$ twins than DC twins. However, fetal growth velocity has not been shown to differ for MC versus DC twins (Smith et al. 2001; Taylor et al. 1998). A host of obstetric and perinatal complications have also been examined extensively in relation to chorionicity. Most studies have found that DC twins are born at older gestational ages than MC twins, and experience fewer morbidities (e.g., patent ductus arteriosus, sepsis, vision and auditory loss, congenital malformations, anemia, intracranial lesions). In general, MC pregnancies are riskier than DC pregnancies.

In contrast to pregnancy and birth outcomes, associations of chorionicity and cognitive, psychiatric, and behavioral outcomes are not as frequently studied or as consistent. The limited literature hints that MC twins have worse cerebral white matter outcomes than DC twins. For example, MC twins have higher cerebral white matter lesions (Adegbite et al. 2005) and a higher incidence of antenatal necrosis of cerebral white matter (Bejar et al. 1990) than DC twins. However, another study showed no differences in clinical neurologic indicators of perinatal asphyxia (van Steenis et al. 2014). In terms of cognitive performance, results are mixed. One study suggested that MC twins have higher rates of pathological nonverbal performance and learning disabilities (Einaudi et al. 2008), whereas other studies showed no difference in mental development indexes (e.g., on the Bayley; Welch et al. 1978; Steingass et al. 2013). Studies examining cerebral palsy are inconsistent, with some suggesting that MC twins are at a higher risk (Burguet et al. 1995, 1999), but others finding no difference in prevalence of cerebral palsy in MC versus DC twins (Steingass et al. 2013; Hack et al. 2009), or that the association was attenuated when controlling on other perinatal factors (Livinec et al. 2005).

\section{Chorionicity and behavioral genetic designs}

We identified 38 articles that examined chorionicity within a behavioral genetic design. Of these, one was excluded 
because no full text was available in English. An additional seven were excluded because chorionicity was not determined via placental pathology or ultrasound. We organized the resulting 30 studies into the following outcome-based categories (although some studies have multiple outcomes across multiple categories): birth weight and early growth, screening/vaccination, handedness, anthropomorphic measures, cognitive/brain measures, and behavioral measures. Reviewed studies are presented in Table 2.

Eight studies examined chorionicity effects on intra-pair associations/differences and/or included chorionicity in classical twin models decomposing the variance in a phenotype into additive genetic (A), common environmental (C), and non-shared environmental (E) influences (e.g., ACE models) in regard to birth weight and early growth patterns. Across these studies, generally it was found that MC twins grew more slowly, were less variable, and less correlated for birth weight than DC twins, and that including chorionicity yielded attenuated, more precise heritability estimates (Buzzard et al. 1983; Vlietinck et al. 1989; Gielen et al. 2008; Touwslager et al. 2010; Welch et al. 1978; Mukherjee et al. 2009; Spitz et al. 1996; Loos et al. 2001a). Although effects were not always significant (e.g., trend-level; Buzzard et al. 1983), the evidence does point to biased heritability estimates in studies of birth weight; where, without accounting for chorionicity, heritability is underestimated.

One study examined screening for trisomy 21 and one examined responses to vaccination (Wojdemann et al. 2006; Gupta et al. 2008). Neither study found evidence of a chorionicity effect on twin similarity. Two studies examined handedness (Carlier et al. 1996; Melnick and Myrianthopoulos 1979). Neither found any effects of chorionicity on twin similarity.

Eleven studies measured various anthropometric measures. Chorionicity effects varied with outcome and over time. For example, MZ-DC twins were more discordant for cholesterol levels from cord blood than MZ-MC twins (Corey et al. 1976). There were significant chorionicity effects when modeled explicitly for height at age 4 years, explaining a small percentage of variance (4\%), but not for weight (Hur and Shin 2008). One study suggested that MZ-MC twins were more discordant than MZ-DC twins for height at 8-12 years (Spitz et al. 1996), however another found that there were no differences in the concordance of MZ-MC and MZ-DC twins for height in at 10-16 years (Gutknecht et al. 1999). MZ-MC twins were more discordant than MZ-DC twins for weight and BMI throughout childhood and adolescence (Gutknecht et al. 1999; Spitz et al. 1996; Mukherjee et al. 2009). There was also some evidence that MZ-MC twins were more similar than MZ-DC twins for saccadic eye movements in adolescence (Blekher et al. 1998). In adults, there were no differences in the twin similarity of various obesity-related measures (or very small effects; Loos et al. 2001a), lung measures, or conventional and ambulatory blood pressure (Loos et al. 2001a; van den Borst et al. 2012; Souren et al. 2007; Fagard et al. 2003). The only significant chorionicity effect on twin similarity found in adults was for fasting fibrinogen: MZ-DC twins were more similar than MZ-MC twins (Loos et al. 2001b). In sum, chorionicity appears to maintain an effect on twin similarity for a variety of anthropometric measures even after birth, but these effects seem to dissipate in later adolescence and adulthood. However the directions of effects varied for each measure. Based on the limited evidence provided here, heritability estimates may be overestimated for cord blood cholesterol, saccadic eye movements, and height at age 4 years. However, heritability estimates may be underestimated for height at 8-12 years, weight and BMI in childhood and adolescence, and fasting fibrinogen in adults.

Eight studies examined cognitive and brain-based measures, and findings were generally mixed. Studies very early in life (e.g., from in utero to 1 year) found no significant effects of chorionicity on twin similarity for head circumference, intracranial volume (Mukherjee et al. 2009), or anterior fontanelle development (Melnick et al. 1980). In toddlerhood, there were no chorionicity effects on twin similarity for the Bayley Mental Development scores (Welch et al. 1978). In childhood, there was evidence of two populations of $\mathrm{MZ}$ twins with regard to variation in IQ, as MZ-MC twins differed from DZ twins but MZ-DC twins did not (Melnick et al. 1978), suggesting considerable influence of the prenatal environment on IQ. However, another study showed that there were no differences in twin similarity based on chorionicity for the McCarthy Scales of Children's Abilities (Sokol et al. 1995). Also in childhood, one study found that MC twins were more similar for arithmetic and vocabulary (with chorionicity explaining 14 and $10 \%$ of the total variance respectively; Jacobs et al. 2001), whereas another found no effect of chorionicity on twin similarity for vocabulary (Spitz et al. 1996). MZ-MC twins were more similar than MZ-DC twins for measures of personality in one study (Sokol et al. 1995), whereas another study found null findings for measures of personality (Gutknecht et al. 1999) in childhood. Some studies found relatively few significant effects of chorionicity on twin similarity (relative to the number of tests examined, e.g., Gutknecht et al. 1999; Spitz et al. 1996). There was only one replicated finding: MZ-MC twins were more similar than MZ-DC twins for the block design but not for vocabulary in children and adults (Spitz et al. 1996; Rose et al. 1981). One reason for the mixed findings in the literature likely is the small sample sizes used to investigate these effects. Nonetheless, there is evidence that chorionicity may have an effect on twin similarity for some cognitive measures, particularly 


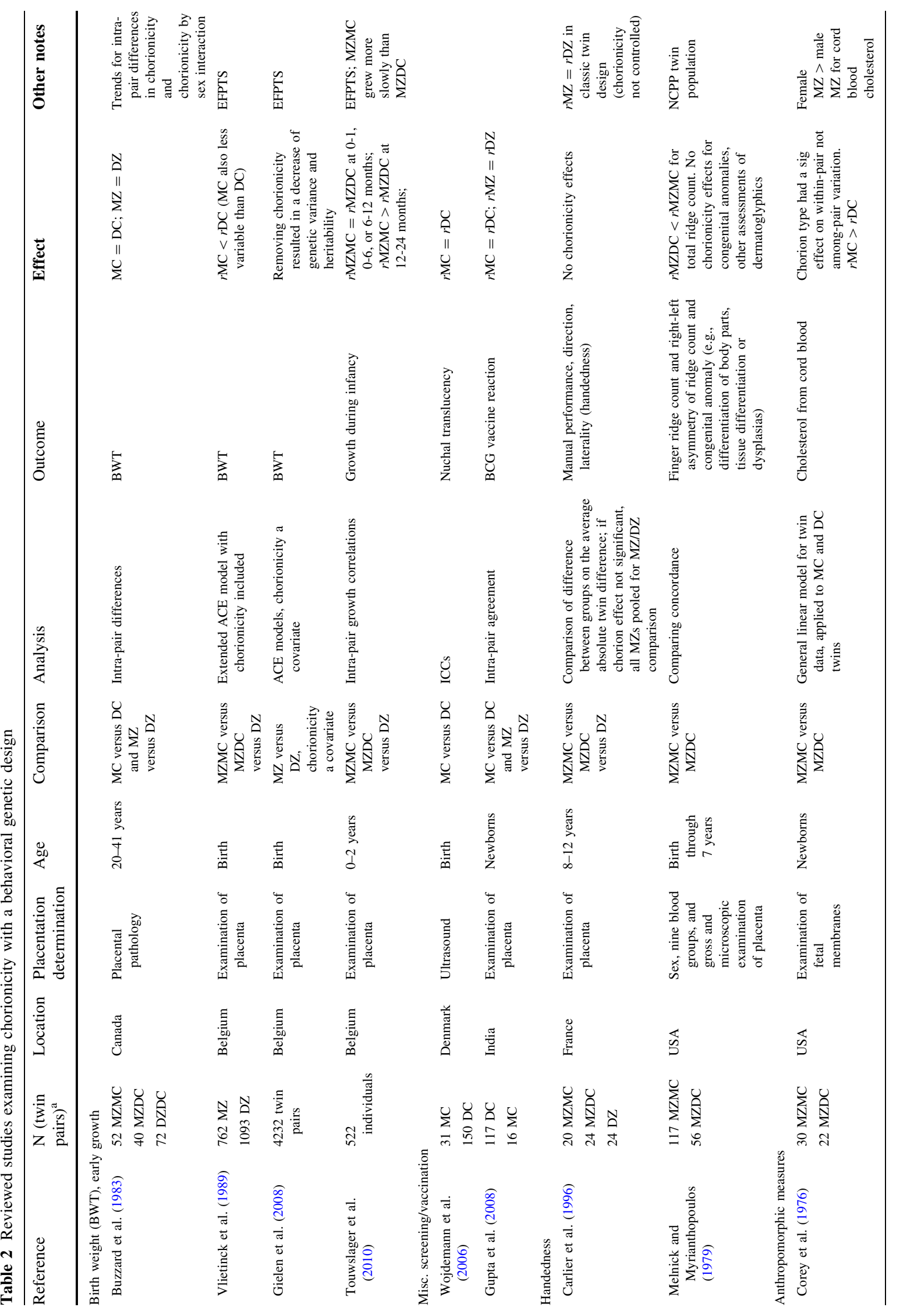




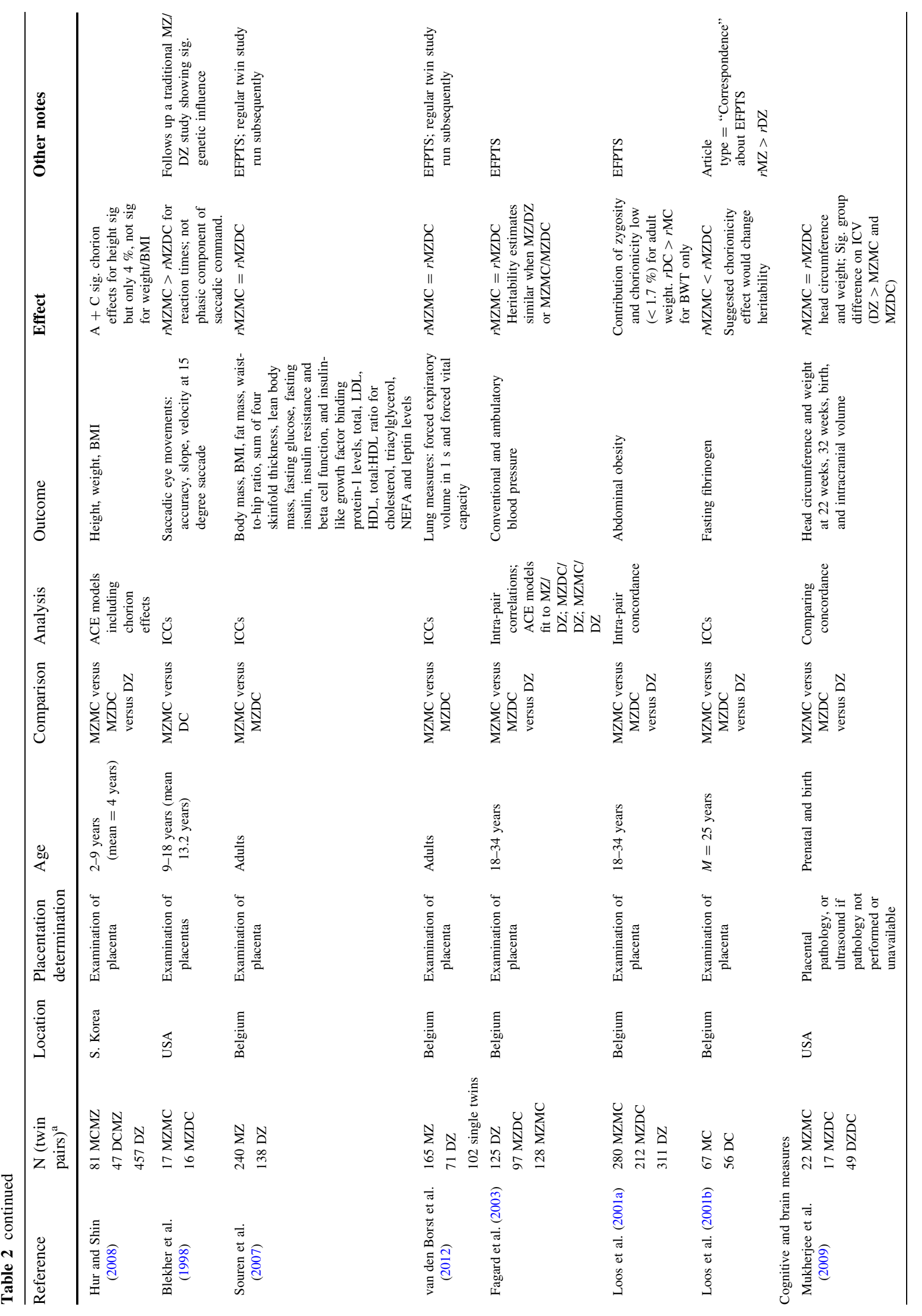




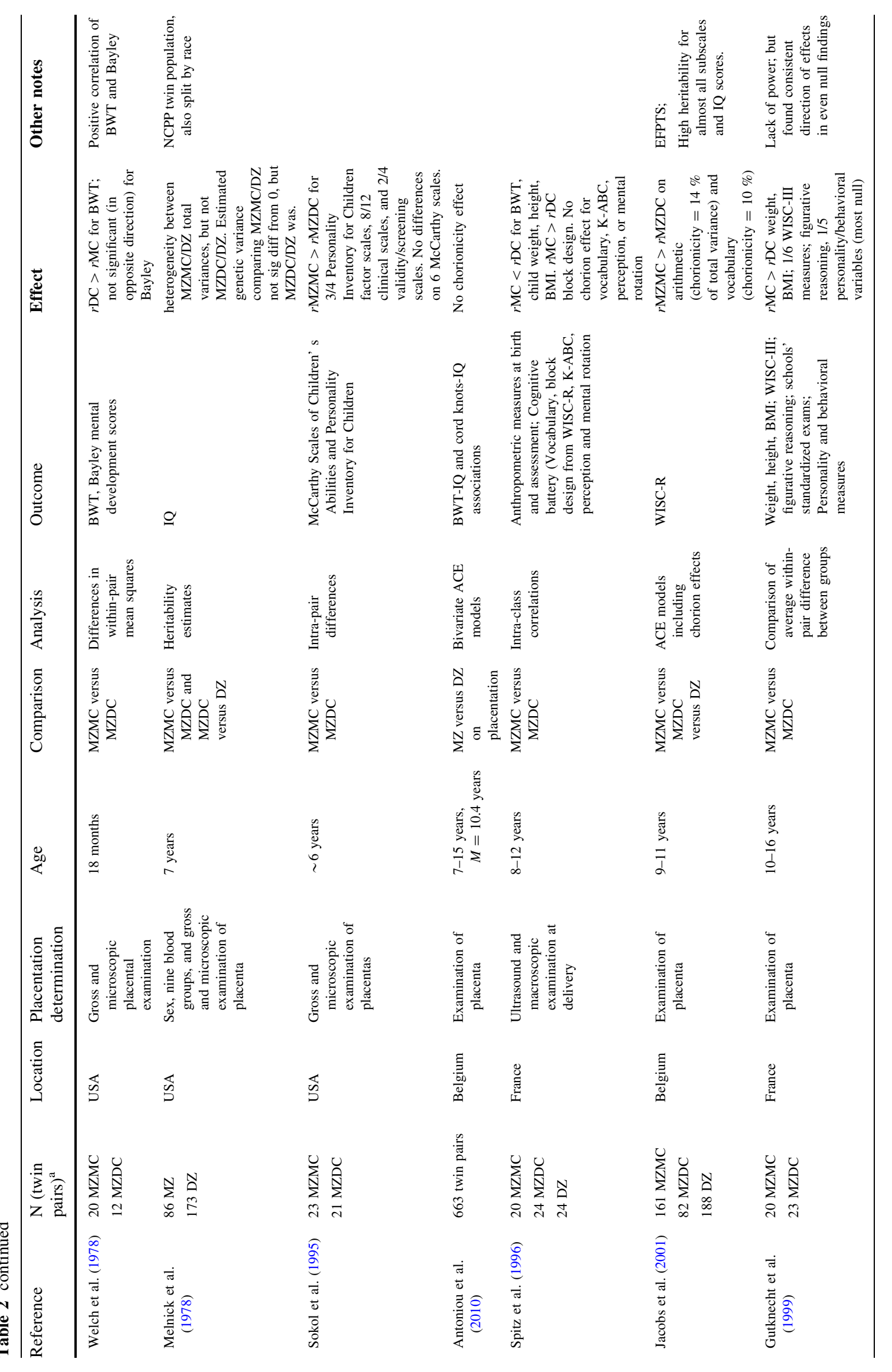




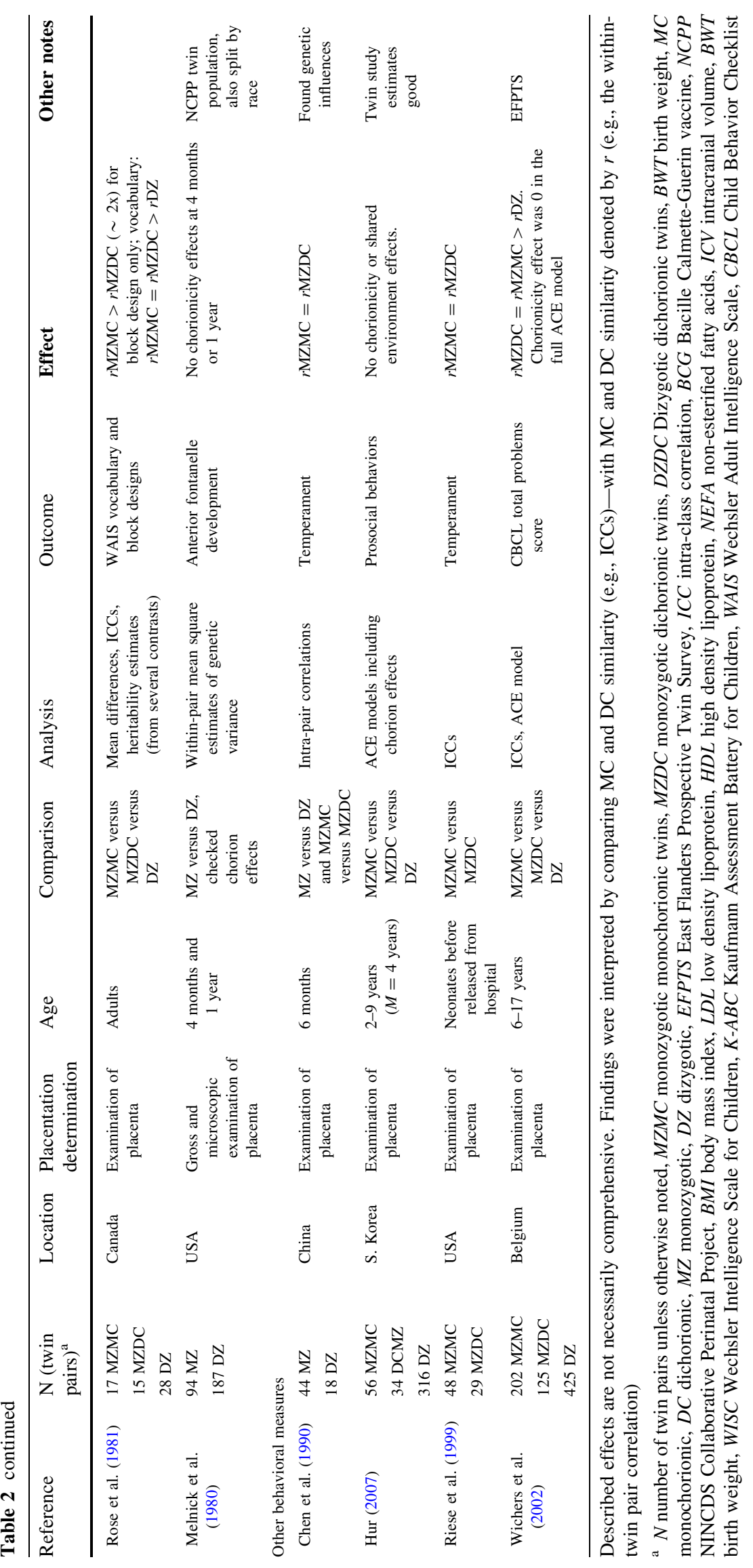


during childhood. When effects were found, MC twins were generally more similar on the cognitive or personality assessment than DC twins were, suggesting that for some cognitive measures heritability estimates may be overestimated when not accounting for chorionicity.

We identified four studies that examined other behavioral phenotypes. For measures of temperament in very early childhood, MC twin similarity was equal to DC twin similarity (Chen et al. 1990; Riese 1999). Similarly, there was no chorionicity effect on twin similarity for prosocial behavior or Child Behavior Checklist (CBCL) total problems in childhood and adolescence (Hur 2007; Wichers et al. 2002). Thus, it is unlikely that chorionicity biases heritability estimates of toddler temperament and child and adolescent prosocial or problem behavior, although the studies were quite small and few in number.

\section{Discussion}

We presented the state of the literature on twin chorionicity in relation to a series of human outcome traits, and addressed the question of to what extent chorionicity differences in MZ twins may influence heritability estimates. We found a large body of literature on the effects of chorionicity on health and behavioral outcomes and a much smaller, but notable body of literature (30 articles in total) that examined chorionicity in relation to twin similarity, which could be used to draw tentative conclusions about whether chorionicity may bias heritability estimates. With only three studies from Asian populations and no studies from African populations, we were unable to draw even tentative conclusions about whether potential chorionicity biases may differ in populations with different twinning rates and $\mathrm{MZ}-\mathrm{MC} / \mathrm{MZ}-\mathrm{DC} / \mathrm{DZ}-\mathrm{DC}$ proportions.

Consistent with the theory that some chorionicity effects could lead to overestimation and others to underestimation of heritability, there were instances of each across the many phenotypes considered here. However, firm conclusions should not be drawn since some of the outcomes were only examined in one or few studies and often sample sizes were small. In this same issue, van Beijsterveldt et al. (2015), using a sample of over 9000 twin pairs, report on chorionicity and heritability estimates on 66 phenotypes, including weight, height, motor milestones, child problem behaviors, cognitive function, wellbeing and personality. For only a few traits, within-pair similarity differed between MC-MZ and DC-MZ pairs. For traits influenced by birth weight, such as weight in young children MC twins were more discordant for 5 out of 13 measures. For traits where blood supply is important, MC-MZ twins were more concordant than DCMZ for 3 traits. van Beijsterveldt et al. conclude that "the influence on the $\mathrm{MZ}$ twin correlation of the intra-uterine prenatal environment, as measured by sharing a chorion type, is small and limited to a few phenotypes".

In our review, we also see that the most robust findings for chorionicity biasing heritability estimates were for birth weight (Vlietinck et al. 1989; Gielen et al. 2008; Touwslager et al. 2010; see Buzzard et al. 1983 for trend effect). This may be due to differences in placental sharing and vascularization between MZ-MC co-twins, which would reduce $\mathrm{MC}$ twin similarity and subsequently underestimate heritability of BW (see Table 1). That chorionicity could lead to underestimates of heritability for birth weight is interesting because despite the low heritability estimates from twin studies for birth weight, recent genome-wide association studies for this phenotype yielded significant hits (Horikoshi et al. 2013; Freathy et al. 2010).

Chorionicity may continue to effect heritability estimates of anthropometric traits later in life, but here effects are attenuated and less consistent. For example, heritability of weight and BMI are likely to be underestimated in childhood and adolescence (Gutknecht et al. 1999; Spitz et al. 1996; Mukherjee et al. 2009), while findings for height are inconsistent (Hur and Shin 2008; Spitz et al. 1996; Gutknecht et al. 1999). By adulthood, chorionicity did not appear to bias heritability estimates for the majority of studied anthropomorphic measures (e.g., various obesity-related measures, lung measures, or conventional and ambulatory blood pressure (Loos et al. 2001a; van den Borst et al. 2012; Souren et al. 2007; Fagard et al. 2003), however, chorionicity had an effect on fasting fibrogen (Loos et al. 2001b). It is important to note that specific outcomes have not been studied systematically. Therefore, it is unclear to what extent chronicity affects specific anthropometric outcomes across development.

Similarly, the effect of chorionicity on cognitive and personality measures in childhood and adolescence was mixed, although when effects were found they pointed to overestimation of heritability estimates. In measures of early brain and cognitive development, chronicity appeared to play no role (Mukherjee et al. 2009; Melnick et al. 1980; Welch et al. 1978). Chorionicity also appeared to play no role in the twin similarity for trisomy 21 , vaccination responses, handedness, toddler temperament, or child and adolescent prosocial or problem behavior. One study found evidence that heritability of was overestimated without accounting for chorionicity (Davis and Phelps 1995; Davis et al. 1995); however, this finding has yet to be replicated.

Taken together, chorionicity biases heritability estimates for some outcomes at some points in during development. It is unclear for which outcomes heritability estimates are likely to be biased in a meaningful or measurable way. This review suggests that outcomes that are related to birth weight are more likely to be influenced by chorionicity. There is also qualitative evidence to suggest that chorionicity effects on heritability may be relatively greater for early compared to 
later developmental outcomes, as was observed with anthropometric traits. With the exception of measures of birth weight and early growth, this review did not find evidence of any replicated effects of chorionicity on the heritability of human traits. Given the wide range of outcomes measured and small sample sizes it is unclear whether chronicity has a measurable effect on behavioral and cognitive measures. It thus would seem that concerns about heritability estimates based on the classical twin design, which relies on the equal environment assumption, are unwarranted when considering the prenatal environment.

Funding This work supported by NIH Grants: DA023134 (Knopik); a 2011 NARSAD Distinguished Investigator Grant [Boomsma: NARSAD (18633)]. Dr. Marceau is supported by T32 DA016184 and T32 MH019927.

\section{Compliance with Ethical Standards}

Conflict of Interest Kristine Marceau, Minni T. B. McMaster, Taylor F. Smith, Joost G. Daams, Catharina E. M. van Beijsterveldt,
Dorret I. Boomsma, and Valerie S. Knopik declare that they have no conflicts of interest.

Human and Animal Rights and Informed Consent This review article does not contain any studies with human participants or animals performed by any of the authors. Each study reviewed in this article is assumed to have been conducted in accordance with the ethical standards of the institutional and/or national research committee and with the 1964 Helsinki declaration and its later amendments or comparable ethical standards. For this type of review, formal consent is not required.

Open Access This article is distributed under the terms of the Creative Commons Attribution 4.0 International License (http://creative commons.org/licenses/by/4.0/), which permits unrestricted use, distribution, and reproduction in any medium, provided you give appropriate credit to the original author(s) and the source, provide a link to the Creative Commons license, and indicate if changes were made. 


\section{Appendix: search strategy}

Appendix 1. Search strategy

Multiples (covered by pubmed search term "multiple birth offspring"):

exp triplets/ or exp twins/ or gemellus or exp triplet pregnancy/ or exp twin pregnancy/ or exp multiple pregnancy/

Specified on:

psychiatry/behavior/intelligence/genetics

CONCEPT 1 [multiples]

("Multiple Birth Offspring"[Mesh] OR Multiple Birth*[tw] OR Sextuplet*[tw] OR quadruplet*[tw] OR quintuplet*[tw] OR triplet*[tw] OR twins[tw] OR twin[tw] OR gemell*[tw] OR "Pregnancy,

Multiple"[Mesh] OR multiple pregnanc*[tw] OR quadruplet pregnan*[tw] OR quintuplet pregnan*[tw] OR triplet pregnan*[tw] OR twin pregnan*[tw])

CONCEPT 2 compare different forms of chorionicity (monochorial dichorial, etc):

("Chorion"[Mesh] OR chorion*[tw] OR monochori*[tw] OR dichori*[tw] OR (("Embryonic and Fetal Development"[Mesh] OR fetal development[tw] OR embryo* development[tw]) AND outcome*[tw]))

Probably too broad:

"Chorion"[Mesh] OR chorion*[tw] OR monochori*[tw] OR dichori*[tw] OR "Placentation"[Mesh] OR placentat*[tw]

Exclusion of animal studies:

NOT ("Animals"[Mesh] NOT "Humans"[Mesh])

Validation set PubMed:

14749653[uid] OR 9610996[uid] OR 16946215[uid] OR 10438438[uid] OR 6682287[uid] OR 18482623[uid] OR 988747[uid] OR 23355123[uid] OR 11084545[uid] OR 23101489[uid] OR 21727159 [uid] OR 11665320[uid] OR 11360946[uid] OR 9822493[uid] OR 21830245[uid] OR 9550178[uid] OR 7487842[uid] OR 12044201 [UID]

PubMed 20140922:

(("Multiple Birth Offspring"[Mesh] OR Multiple Birth*[tw] OR Sextuplet*[tw] OR quadruplet*[tw] OR quintuplet*[tw] OR triplet*[tw] OR twins[tw] OR twin[tw] OR gemell*[tw] OR "Pregnancy,

Multiple"[Mesh] OR multiple pregnanc*[tw] OR quadruplet pregnan*[tw] OR quintuplet pregnan*[tw] OR triplet pregnan*[tw] OR twin pregnan*[tw]) AND ("Chorion"[Mesh] OR chorion*[tw] OR monochori*[tw] OR dichori*[tw] OR (("Embryonic and Fetal Development"[Mesh] OR fetal development[tw] OR embryo* development[tw]) AND outcome*[tw]))) NOT ("Animals"[Mesh] NOT "Humans"[Mesh])

Added later:

(twin discordan*[tw] OR twin concordan*[tw] OR ((twin[tiab] or twins[tiab]) AND (concordan*[tiab] OR discordan*[tiab])) and outcome*[tw])

Speficications:

Genetics:

genetic*[tw] OR epigenetic*[tw] OR gene[tw] OR genes[tw] OR intelligence[tw] OR iq[tw] OR genotyp*[tw] geno typ*[tw] OR phenotyp*[tw] OR pheno typ*[tw] OR "genetics" [Subheading] OR "Genetic Techniques"[Mesh] OR "Genetics"[Mesh] OR "Congenital, Hereditary, and Neonatal Diseases and Abnormalities"[Mesh] OR "Genetic Phenomena"[Mesh]

Psychiatry/behavior:

"Psychiatry and Psychology Category"[Mesh] OR "psychology" [Subheading] OR psychiatr*[tw] OR mental[tw] OR psycholog*[tw] OR behavior*[tw] OR neuropsych*[tw]

"Neurologic manifestations":

nervous system diseases[mh] OR neuromorbidity[tw] OR neurologic*[tw]

Final search, PubMed 20150119 (20150119: 2111 hits / after deleting double records): ((("Multiple Birth Offspring"[Mesh] OR Multiple Birth*[tw] OR Sextuplet*[tw] OR quadruplet*[tw] OR quintuplet*[tw] OR triplet*[tw] OR twins[tw] OR twin[tw] OR gemell*[tw] OR "Pregnancy, Multiple"[Mesh] OR multiple pregnanc*[tw] OR quadruplet pregnan*[tw] OR quintuplet pregnan*[tw] OR triplet pregnan*[tw] OR twin pregnan*[tw]) AND ("Chorion"[Mesh] OR chorion*[tw] OR monochori*[tw] OR dichori*[tw] OR (("Embryonic and Fetal Development"[Mesh] OR fetal development [tw] OR embryo* development[tw]) AND outcome*[tw])) OR (twin discordan*[tw] OR twin concordan*[tw] OR ((twin[tiab] or twins[tiab]) AND (concordan*[tiab] OR discordan*[tiab])) and outcome*[tw])) AND (genetic*[tw] OR epigenetic*[tw] OR gene[tw] OR genes[tw] OR intelligence[tw] OR iq[tw] OR genotyp*[tw] geno typ*[tw] OR phenotyp*[tw] OR pheno typ*[tw] OR "genetics" [Subheading] OR "Genetic Techniques"[Mesh] OR "Genetics"[Mesh] OR "Congenital, Hereditary, and Neonatal Diseases and Abnormalities"[Mesh] OR "Genetic Phenomena"[Mesh] OR "Psychiatry and Psychology Category"[Mesh] OR "psychology" [Subheading] OR psychiatr*[tw] OR mental[tw] OR psycholog*[tw] OR behavior*[tw] OR neuropsych*[tw] OR nervous system diseases[mh] OR neuromorbidity[tw] OR neurologic*[tw])) NOT ("Animals"[Mesh] NOT "Humans"[Mesh]) 
Embase 1947 to Present, OvidSP, 20150119 (20150119: 1455 hits/after deleting double records): exp multiple pregnancy/ or exp twins/

(multiple birth or multiple offspring or Sextuplet* OR quadruplet* OR quintuplet* OR triplet* OR twins OR twin OR gemell* OR multiple pregnanc* OR quadruplet pregnan* OR quintuplet pregnan* OR triplet pregnan* OR twin pregnan*).ab,kw,ti

or/ $1-2$

chorion/

(chorion* OR monochori* OR dichori*).ab,kw,ti

embryo development/ or fetus development/

((embryo* OR fetus OR fetal) ADJ3 development).ab,kw,ti

6 or 7

outcome?.mp

8 and 9

4 or 5 or 10

3 and 11

twin concordance/ or twin discordance/

((discordan* or concordan*) adj3 twin?).ab,kw,ti.

9 and (13 or 14)

12 or 15

gene/ or genetics/ OR genetic procedures/ or congenital disorder/ OR heridity/

(genetic* OR epigenetic* OR gene? OR intelligence OR iq OR genotyp* geno typ* OR phenotyp* OR pheno typ*).ab,kw,ti

exp psychiatry/ or exp psychology/

(psychiatr* OR mental OR psycholog* OR behavior* OR neuropsych*).ab,kw,ti

exp neurologic disease/

(neuromorbidity OR neurologic*).ab,kw,ti

or/ $17-22$

16 and 23

(animal/ or animal experiment/ or animal model/ or nonhuman/ or rat/ or mouse/ or (rat or rats or mouse or mice).ti.) not human/

24 not 25

..dedup 26

Validation set (19 records):

("23355123" OR "2013110881" OR "21830245" OR "2011467101" OR "2008220392" OR

"2006431534" OR "2004056200" OR "2002202403" OR "2001184521" OR "2000413754" OR

"1999283616" OR "1998397679" OR "1998179819" OR "1998106571" OR "1995299640" OR

"1983121977" OR "0977184937" OR "2001343682" OR "2013644154").an

Comment: twin (dis/con)cordance in combination with outcome searched for separately because of poor representation of chrorionicity in bibliographic records.

PsycINFO 1806 to Present, 20150119 (138 hits)

exp multiple births/

(multiple birth or multiple offspring or Sextuplet* OR quadruplet* OR quintuplet* OR triplet* OR twins OR twin OR gemell* OR multiple pregnanc* OR quadruplet pregnan* OR quintuplet pregnan* OR triplet pregnan* OR twin pregnan*).ab,id,ti

or/ $1-2$

(chorion* OR monochori* OR dichori*).ab,id,ti

prenatal development/

((embryo* OR fetus OR fetal) ADJ3 development).ab,id,ti

5 or 6

outcome?.mp

7 and 8

4 or 9

3 and 10

((discordan* or concordan*) adj3 twin?).ab,id,ti.

8 and 12

11 or 13

..dedup 15

(1996-16528-001 or 2002-01801-013).an 


\section{References}

Adegbite AL, Castille S, Ward S, Bajoria R (2005) Prevalence of cranial scan abnormalities in preterm twins in relation to chorionicity and discordant birth weight. Eur J Obstet Gynecol Reprod Biol 119(1):47-55. doi:10.1016/j.ejogrb.2004.06.016

Ananth CV, Vintzileos AM, Shen-Schwarz S, Smulian JC, Lai YL (1998) Standards of birth weight in twin gestations stratified by placental chorionicity. Obstet Gynecol 91(6):917-924

Antoniou EE, Fowler T, Thiery E, Southwood T, Van Gestel S, Jacobs $\mathrm{N}$ et al (2010) Intrauterine environment and cognitive development in young twins. [Conference Abstract]. Twin Res Hum Genet. 13(3):246

Audibert F, Gagnon A (2011) Prenatal screening for and diagnosis of aneuploidy in twin pregnancies. J Obstet Gynaecol Can 33(7): 754-767

Baghdadi S, Gee H, Whittle MJ, Khan KS (2003) Twin pregnancy outcome and chorionicity. Acta Obstet Gynecol Scand 82(1):18-21

Bajoria R, Sooranna SR, Ward S, D'Souza S, Hancock M (2001) Placental transport rather than maternal concentration of amino acids regulates fetal growth in monochorionic twins: implications for fetal origin hypothesis. Am J Obstet Gynecol 185(5):1239-1246. doi:10.1067/mob.2001.118269

Barker DJ (1990) The fetal and infant origins of adult disease. BMJ 301(6761):1111

Bejar R, Vigliocco G, Gramajo H, Solana C, Benirschke K, Berry C et al (1990) Antenatal origin of neurologic damage in newborn infants. II. Multiple gestations. Am J Obstet Gynecol 162(5):1230-1236

Blekher T, Christian JC, Abel LA, Yee RD (1998) Influences of chorion type on saccadic eye movements in twins. Invest Ophthalmol Vis Sci 39(11):2186-2190

Burguet A, Menget A, Monnet E, Allemand H, Gasca-Avanzi A, Laithier V et al (1995) Neurologic development in premature infants under 33 weeks of gestational age: determination of risk of neurological abnormalities in a prospective regional survey with a control group. Arch Pediatr 2(12):1157-1165

Burguet A, Monnet E, Pauchard JY, Roth P, Fromentin C, Dalphin ML et al (1999) Some risk factors for cerebral palsy in very premature infants: importance of premature rupture of membranes and monochorionic twin placentation. Biol Neonate 75(3):177-186. doi:10.1159/000014094

Buzzard IM, Uchida IA, Norton JA Jr, Christian JC (1983) Birth weight and placental proximity in like-sexed twins. Am J Hum Genet 35(2):318-323

Carlier M, Spitz E, Vacher-Lavenu MC, Villeger P (1996) Manual performance and laterality in twins of known chorion type. Behav Genet 26(4):409-417. doi:10.1007/BF02359485

Chang YL (2008) Monochorionic twin with selective intrauterine growth restriction. [Review]. J Med Ultrasound 16(3):194-201. doi:10.1016/S0929-6441\%2808\%2960048-X

Chen CJ, Yu MW, Wang CJ, Tong SL, Tien M, Lee TY et al (1990) Genetic variance and heritability of temperament among Chinese twin infants. [Conference Paper]. Acta Genet Med Gemellol (Roma) 39(4):485-490

Cleary-Goldman J, D'Alton ME (2008) Growth abnormalities and multiple gestations. Semin Perinatol 32(3):206-212. doi:10. 1053/j.semperi.2008.02.009

Corey LA, Kang KW, Christian JC, Norton JA Jr, Harris RE, Nance WE (1976) Effects of chorion type on variation in cord blood cholesterol of monozygotic twins. Am J Hum Genet 28(5):433-441

Davis JO, Phelps JA (1995) Twins with schizophrenia: genes or germs? Schizophr Bull 21(1):13-18

Davis JO, Phelps JA, Bracha HS (1995) Prenatal development of monozygotic twins and concordance for schizophrenia. Schizophr Bull 21(3):357-366
De Paepe ME (2015) Examination of the twin placenta. Semin Perinatol 39(1):27-35. doi:10.1053/j.semperi.2014.10.005

Derom R, Bryan E, Derom C, Keith L, Vlietinck R (2001) Twins, chorionicity and zygosity. Twin Res 4(3):134-136

Derom C, Derom R, Loos RJ, Jacobs N, Vlietinck R (2003) Retrospective determination of chorion type in twins using a simple questionnaire. Twin Res 6(1):19-21

Einaudi MA, Busuttil M, Monnier AS, Chanus I, Palix C, Gire C (2008) Neuropsychological screening of a group of preterm twins: comparison with singletons. Childs Nerv Syst 24(2): 225-230. doi:10.1007/s00381-007-0422-6

Fagard RH, Loos RJ, Beunen G, Derom C, Vlietinck R (2003) Influence of chorionicity on the heritability estimates of blood pressure: a study in twins. J Hypertens 21(7):1313-1318. doi:10. 1097/01.hjh.0000059072.43904.07

Foley DL, Neale MC, Kendler KS (2000) Does intra-uterine growth discordance predict differential risk for adult psychiatric disorder in a population-based sample of monozygotic twins? Psychiatr Genet 10(1):1-8

Freathy RM, Mook-Kanamori DO, Sovio U, Prokopenko I, Timpson NJ, Berry DJ et al (2010) Variants in ADCY5 and near CCNL1 are associated with fetal growth and birth weight. Nat Genet 42(5):430-435. doi:10.1038/ng.567 http://www.nature.com/ng/ journal/v42/n5/suppinfo/ng.567_S1.html

Gielen M, Lindsey PJ, Derom C, Smeets HJ, Souren NY, Paulussen $\mathrm{AD}$ et al (2008) Modeling genetic and environmental factors to increase heritability and ease the identification of candidate genes for birth weight: a twin study. Behav Genet 38(1):44-54. doi:10.1007/s10519-007-9170-3

Gupta P, Faridi MM, Shah D, Dev G (2008) BCG reaction in twin newborns: effect of zygosity and chorionicity. Indian Pediatr 45(4):271-277

Gutknecht L, Spitz E, Carlier M (1999) Long-term effect of placental type on anthropometrical and psychological traits among monozygotic twins: a follow up study. Twin Res 2(3): $212-217$

Hack KE, Koopman-Esseboom C, Derks JB, Elias SG, de Kleine MJ, Baerts W et al (2009) Long-term neurodevelopmental outcome of monochorionic and matched dichorionic twins. PLoS ONE 4(8):e6815. doi:10.1371/journal.pone.0006815

Hall JG (2003) Twinning. Lancet 362(9385):735-743. doi:10.1016/ S0140-6736(03)14237-7

Haverkamp F, Lex C, Hanisch C, Fahnenstich H, Zerres K (2001) Neurodevelopmental risks in twin-to-twin transfusion syndrome: preliminary findings. Eur J Paediatr Neurol 5(1):21-27. doi:10. 1053/ejpn.2001.0400

Herranz G (2015) The timing of monozygotic twinning: a criticism of the common model. Zygote 23(01):27-40. doi:10.1017/S09 67199413000257

Hoekstra C, Zhao ZZ, Lambalk CB, Willemsen G, Martin NG, Boomsma DI et al (2008) Dizygotic twinning. Hum Reprod Update 14(1):37-47. doi:10.1093/humupd/dmm036

Horikoshi M, Yaghootkar H, Mook-Kanamori DO, Sovio U, Taal HR, Hennig BJ et al (2013) New loci associated with birth weight identify genetic links between intrauterine growth and adult height and metabolism. Nat Genet 45(1): 76-82. doi:10.1038/ng. 2477 http://www.nature.com/ng/journal/v45/n1/abs/ng.2477.html\# supplementary-information

Hur YM (2007) Effects of the chorion type on prosocial behavior in young South Korean twins. Twin Res Hum Genet 10(5): 773-777. doi:10.1375/twin.10.5.773

Hur YM, Shin JS (2008) Effects of chorion type on genetic and environmental influences on height, weight, and body mass index in South Korean young twins. Twin Res Hum Genet 11(1):63-69. doi:10.1375/twin.11.1.63 
Jacobs N, Gestel SV, Derom C, Thiery E, Vernon P, Derom R et al (2001) Heritability estimates of intelligence in twins: effect of chorion type. Behav Genet 31(2):209-217. doi:10.1023/A: 1010257512183

Knopman JM, Krey LC, Oh C, Lee J, McCaffrey C, Noyes N (2014) What makes them split? Identifying risk factors that lead to monozygotic twins after in vitro fertilization. Fertil Steril 102(1):82-89. doi:10.1016/j.fertnstert.2014.03.039

Lamb DJ, Vink JM, Middeldorp CM, van Beijsterveldt CE, Haak MC, Overbeek LI et al (2012) Effects of chorionicity and zygosity on triplet birth weight. Twin Res Hum Genet 15(2):149-157. doi:10.1375/twin.15.2.149

Lenis-Cordoba N, Sanchez MA, Bello-Munoz JC, Sagala-Martinez J, Campos N, Carreras-Moratonas E et al (2013) Amniocentesis and the risk of second trimester fetal loss in twin pregnancies: results from a prospective observational study. J Matern Fetal Neonatal Med 26(15):1537-1541. doi:10.3109/14767058.2013.791271

Livinec F, Ancel PY, Marret S, Arnaud C, Fresson J, Pierrat V et al (2005) Prenatal risk factors for cerebral palsy in very preterm singletons and twins. Obstet Gynecol 105(6):1341-1347. doi:10. 1097/01.AOG.0000161375.55172.3f

Loehlin JC, Nichols RC (1976) Heredity, environment and personality. University of Texas Press, Austin

Loos RJ, Beunen G, Fagard R, Derom C, Vlietinck R (2001a) The influence of zygosity and chorion type on fat distribution in young adult twins consequences for twin studies. Twin Res 4(5):356-364. doi:10.1375/1369052012524

Loos RJ, Beunen G, Fagard R, Derom C, Vlietinck R, Phillips DI (2001b) Twin studies and estimates of heritability. Lancet 357(9266):1445. doi:10.1016/s0140-6736(00)04594-3

Machin G (2001) Placentation in multiple births. Twin Res 4(3):150-155. doi:10.1375/1369052012254

Machin G (2004) Why is it important to diagnose chorionicity and how do we do it? [Review]. Best Pract Res 18(4):515-530. doi:10.1016/j.bpobgyn.2004.04.013

Machin G (2009) Non-identical monozygotic twins, intermediate twin types, zygosity testing, and the non-random nature of monozygotic twinning: a review. Am J Med Genet C Semin Med Genet 151c(2):110-127. doi:10.1002/ajmg.c.30212

Machin G, Bamforth F (1996) Zygosity and placental anatomy in 15 consecutive sets of spontaneously conceived triplets. Am J Med Genet 61(3):247-252. doi:10.1002/(sici)1096-8628(19960122)61: $3<247$ :aid-ajmg8>3.0.co;2-r

Melmed S, Polonsky KS, Larsen PR, Kronenberg HM (2012) Williams textbook of endocrinology, 12th edn. Saunders, Philadelphia

Melnick M, Myrianthopoulos NC (1979) The effects of chorion type on normal and abnormal developmental variation in monozygous twins. Am J Med Genet 4(2):147-156. doi:10.1002/ajmg.1320 040207

Melnick M, Myrianthopoulos NC, Christian JC (1978) The effects of chorion type on variation in IQ in the NCPP twin population. Am J Hum Genet 30(4):425-433

Melnick M, Myrianthopoulos NC, Christian JC (1980) Estimates of genetic variance for anterior fontanelle development in the NCPP twin population. Acta Genet Med Gemellol (Roma) 29(2):151-155

Mukherjee N, Kang C, Wolfe HM, Hertzberg BS, Smith JK, Lin W et al (2009) Discordance of prenatal and neonatal brain development in twins. Early Hum Dev 85(3):171-175. doi:10. 1016/j.earlhumdev.2008.07.008

Munsinger H (1977) The identical-twin transfusion syndrome: a source of error in estimating IQ resemblance and heritability. Ann Hum Genet 40(3):307-321

Nikkels PG, Hack KE, van Gemert MJ (2008) Pathology of twin placentas with special attention to monochorionic twin placentas. J Clin Pathol 61(12):1247-1253. doi:10.1136/jcp.2008.055210
O'Brien P, Hay DA (1987) Birthweight differences, the transfusion syndrome and the cognitive development of monozygotic twins. Acta Geneticae Medicae et Gemellologiae 36(2):181-196

Page KR (1993) The physiology of the human placenta. Kings Lynn and Guilford Biddles Ltd, London

Petterson B, Blair E, Watson L, Stanley F (1998) Adverse outcome after multiple pregnancy. Baillieres Clin Obstet Gynaecol 12(1):1-17

Phelps JA, Davis JO, Schartz KM (1997) Nature, nurture, and twin research strategies. Curr Dir Psychol Sci 6(5):117-121. doi:10. 1111/1467-8721.ep10772877

Phillips DI (1993) Twin studies in medical research: can they tell us whether diseases are genetically determined? Lancet 341: 1008-1009

Prescott CA, Johnson RC, McArdle JJ (1999) Chorion type as a possible influence on the results and interpretation of twin study data. Twin Res 2(4):244-249

Price B (1950) Primary biases in twin studies: a review of prenatal and natal difference-producing factors in monozygotic pairs. Am J Hum Genet 2:293-352

Reed T, Uchida IA, Norton JA Jr, Christian JC (1978) Comparisons of dermatoglyphic patterns in monochorionic and dichorionic monozygotic twins. Am J Hum Genet 30(4):383-391

Reed T, Christian JC, Wood PD, Schaefer EJ (1991) Influence of placentation on high density lipoproteins in adult males: the NHLBI twin study. Acta Genet Med Gemellol (Roma) 40(3-4):353-359

Reed T, Pfefferbaum A, Sullivan EV, Carmelli D (2002) Influences of chorion type on measurements of the corpus callosum in adult monozygotic male twins? Am J Hum Biol 14(3):338-346. doi:10.1002/ajhb.10027

Riese ML (1999) Effects of chorion type on neonatal temperament differences in monozygotic twin pairs. Behav Genet 29(2):87-94

Rose RJ, Uchida IA, Christian JC (1981) Placentation effects on cognitive resemblance of adult monozygotes. Prog Clin Biol Res 69(Pt B):35-41

Scarr S, Carter-Saltzman L (1979) Twin method: defense of a critical assumption. Behav Genet 9(6):527-542. doi:10.1007/BF01067349

Schneider H (1991) Placental transport function. Reprod Fertil Dev 3(4):345-353. doi:10.1071/RD9910345

Shrim A, Weisz B, Gindes L, Gagnon R (2010) Parameters associated with outcome in third trimester monochorionic diamniotic twin pregnancies. J Obstet Gynaecol Can 32(5):429-434

Smith APM, Ong S, Smith NCS, Campbell D (2001) A prospective longitudinal study of growth velocity in twin pregnancy. Ultrasound Obstet Gynecol 18(5):485-487. doi:10.1046/j.09607692.2001.00519.x

Smits J, Monden C (2011) Twinning across the developing world. PLoS ONE 6(9):e25239. doi:10.1371/journal.pone.0025239

Sokol DK, Moore CA, Rose RJ, Williams CJ, Reed T, Christian JC (1995) Intrapair differences in personality and cognitive ability among young monozygotic twins distinguished by chorion type. Behav Genet 25(5):457-466

Souren NY, Paulussen AD, Loos RJ, Gielen M, Beunen G, Fagard R et al (2007) Anthropometry, carbohydrate and lipid metabolism in the east flanders prospective twin survey: heritabilities. Diabetologia 50(10):2107-2116. doi:10.1007/s00125-007-0784-z

Souter VL, Kapur RP, Nyholt DR, Skogerboe K, Myerson D, Ton CC et al (2003) A report of dizygous monochorionic twins. N Engl J Med 349(2):154-158. doi:10.1056/NEJMoa030050

Spitz E, Carlier M, Vacher-Lavenu M-C, Reed T (1996) Long-term effect of prenatal heterogeneity among monozygotes. Curr Psychol Cognit 15(3):283-308

Steingass KJ, Taylor HG, Wilson-Costello D, Minich N, Hack M (2013) Discordance in neonatal risk factors and early childhood outcomes of very low birth weight $(<1.5 \mathrm{~kg})$ twins. J Perinatol 33(5):388-393. doi:10.1038/jp.2012.121 
Steinman G (2001) Mechanisms of twinning. I. Effect of environmental diversity on genetic expression in monozygotic multifetal pregnancies. J Reprod Med 46(5):467-472

Taylor GM, Owen P, Mires GJ (1998) Foetal growth velocities in twin pregnancies. Twin Res 1(1):9-14

Tong S, Caddy D, Short RV (1997) Use of dizygotic to monozygotic twinning ratio as a measure of fertility. Lancet 349(9055): 843-845. doi:10.1016/S0140-6736(96)10003-9

Touwslager RNH, Gielen M, Derom C, Mulder ALM, Gerver WJM, Zimmermann LJ et al (2010) Determinants of infant growth in four age windows: a twin study. [Conference Abstract]. Twin Res Hum Genet 13(3):290

van Beijsterveldt CEM, Overbeek LIH, Rozendaal L, McMaster MTB, Glasner TJ, Bartels M et al (2015) Chorionicity and heritability estimates from twin studies: the prenatal environment of twins and their resemblance across a large number of traits. Behav Genet. doi:10.1007/s10519-015-9745-3

van den Borst B, Souren NY, Loos RJ, Paulussen AD, Derom C, Schols AM et al (2012) Genetics of maximally attained lung function: a role for leptin? Respir Med 106(2):235-242. doi:10. 1016/j.rmed.2011.08.001 van der Aa E, Copius Peereboom-Stegeman JJ, Noordhoek J, Gribnau FJ, Russel FM (1998) Mechanisms of drug transfer across the human placenta. Pharm World Sci 20(4):139-148. doi:10.1023/ A: 1008656928861

van Steenis A, Kromhout HE, Steggerda SJ, Sueters M, Rijken M, Oepkes D et al (2014) Perinatal asphyxia in monochorionic versus dichorionic twins: incidence, risk factors and outcome. Fetal Diagn Ther 35(2):87-91. doi:10.1159/000356433

Vlietinck R, Derom R, Neale MC, Maes H, van Loon H, Derom C et al (1989) Genetic and environmental variation in the birth weight of twins. Behav Genet 19(1):151-161

Welch P, Black KN, Christian JC (1978) Placental type and Bayley Mental Development scores in 18-month-old twins. Prog Clin Biol Res 24a:145-149

Wichers MC, Danckaerts M, Van Gestel S, Derom C, Vlietink R, van Os J (2002) Chorion type and twin similarity for child psychiatric symptoms. Arch Gen Psychiatr 59(6):562-564

Wojdemann KR, Larsen SO, Shalmi AC, Sundberg K, Tabor A, Christiansen M (2006) Nuchal translucency measurements are highly correlated in both mono- and dichorionic twin pairs. Prenat Diagn 26(3):218-220. doi:10.1002/pd.1382 